\title{
Elaboração do Diagnóstico Rápido Participativo (DRP) Para o Projeto PLANTAR - Plano Técnico de Articu- lação de Rede de Proteção e Defesa dos Direitos da Pessoa Idosa, no Município do Rio de Janeiro-RJ Ellaboration of the Participatory Rapid Diagnosis (DRP) for PLANTAR - Plan for Technical Coordination Network for Pro- tecting and Defending the Rights of the Elderly in the city of Rio de Janeiro-RJ, Brazil
}

\section{Introdução}

Em maio de 2006, em Brasília-DF, realizou-se a I Conferência Nacional dos Direitos da Pessoa Idosa, que resultou no compromisso de construir a Rede Nacional de Proteção e Defesa da Pessoa Idosa - RENADI ${ }^{1}$. Em 2009, A II Conferência Nacional dos Direitos da Pessoa Idosa, tendo como diretriz a "Avaliação da RENADI - Rede Nacional de Proteção e Defesa da Pessoa Idosa, avanços e desafios", ${ }^{2}$ apontou para a reflexão e construção de novos caminhos, visando efetivar direitos fundamentados na Constituição Federal de 1988, ${ }^{3}$ na Política Nacional do Idoso ${ }^{4}$ e no Estatuto do Idoso, ${ }^{5}$ e investir em novas estratégias contra a violência e a discriminação à pessoa idosa.

Para a integração de políticas de promoção de defesa dos direitos da pessoa idosa foi criado um plano de articulação de redes, visando fornecer ao gestor ferramentas que facilitem e deem eficiência ao planejamento, integração e articulação. Este plano é o PLANTAR - Plano Técnico de Articulação de Rede de Promoção dos Direitos da Pessoa Idosa .

O PLANTAR tem por objetivos integrar políticas para a construção de uma agenda comum de trabalho - entre governos, sociedade civil e organismos internacionais - visando ao desenvolvimento de ações de valorização da pessoa idosa e desenvolver mecanismos para organização, fortalecimento e integração dos serviços locais, assegurando a participação social na construção de todos os processos. As metas são criar e/ou fortalecer redes de proteção e defesa dos direitos da pessoa idosa e despertar consciência na sociedade e nos formadores de opinião sobre os direitos da pessoa idosa. Nas ferramentas de articulação encontram-se ações
Sandra Rabello ${ }^{1}$, Conceição Ramos de Abreu ${ }^{2}$

\section{Resumo}

Objetivos: Trata-se de um relato de experiência, cujo objetivo é descrever a participação da Universidade do Estado do Rio de Janeiro - UERJ na aplicação do questionário do projeto piloto PLANTAR, pela metodologia do Diagnóstico Rápido Participativo. Metodologia: O projeto PLANTAR Plano Técnico de Articulação de Rede de Proteção e Defesa dos Direitos da Pessoa Idosa tem como metodologia integrar políticas para construção de uma agenda comum de trabalho entre governos, sociedade civil e governos internacionais, por intermédio da aplicação de seis questionários que permitem coletar dados sobre a população idosa local e levantar as condições das políticas públicas voltadas para pessoas idosas. Resultados: Foi identificada necessidade de investimentos no projeto, nas áreas de capacitação de pessoal, em recursos didáticos, em informativos à população através da mídia, e em maior participação das organizações não governamentais. Conclusões: o município do Rio de Janeiro possui uma rede de serviços, mas ela não está articulada, o que dificulta uma atuação eficaz.

Palavras-chaves: Rede Socioassistencial; Pesquisa; Diagnóstico Participativo; Políticas Sociais Públicas

Área Temática: Direitos Humanos e Justiça Linha de Extensão: Terceira Idade
' Coordenadora de Projetos de Extensão da UnATI/UERJ, membro do Conselho Estadual de Defesa da Pessoa Idosa do Rio de Janeiro, coordenadora do curso de Orientação e Informação para Familiares e Acompanhantes de Idosos (UnATI/UERJ). E-mail: srabello.uerj@gmail.com

2 Editora Executiva do periódico científico Revista Brasileira de Geriatria e Gerontologia, publicação do Centro de Referência e Documentação sobre Envelhecimento (UnATI/ UERJ). E-mail: abreucr@yahoo.com.br 
de grande relevância à implementação do Projeto PLANTAR, sendo uma delas o Diagnóstico Rápido Participativo (DRP). O DRP é uma ferramenta aplicada com o objetivo de auxiliar os interessados em conhecer a complexa teia de relações que permeiam o cotidiano dos grupos sociais, na medida em que permite uma visão mais real dos inúmeros fatores - sociais, econômicos, ambientais e culturais - que afetam as tomadas de decisão nesses sistemas.

\section{Objetivo}

O objetivo deste trabalho é relatar os resultados da realização do Diagnóstico Rápido Participativo (DRP) no município do Rio de Janeiro, sob a coordenação da Universidade do Estado do Rio de Janeiro - UERJ, como ferramenta do PLANTAR - Plano Técnico de Articulação de Rede de Promoção dos Direitos da Pessoa Idosa.

\section{O Projeto PLANTAR e a sua implementação no município do Rio de Janeiro}

"A cidade do Rio de Janeiro foi escolhida como a primeira a participar do PLANTAR, por possuir uma das maiores populações idosas do país. De acordo com o Instituto Brasileiro de Geografia e Estatística (IBGE), em 2008, eram 1,7 milhão ou $14,7 \%$ da população local"?.

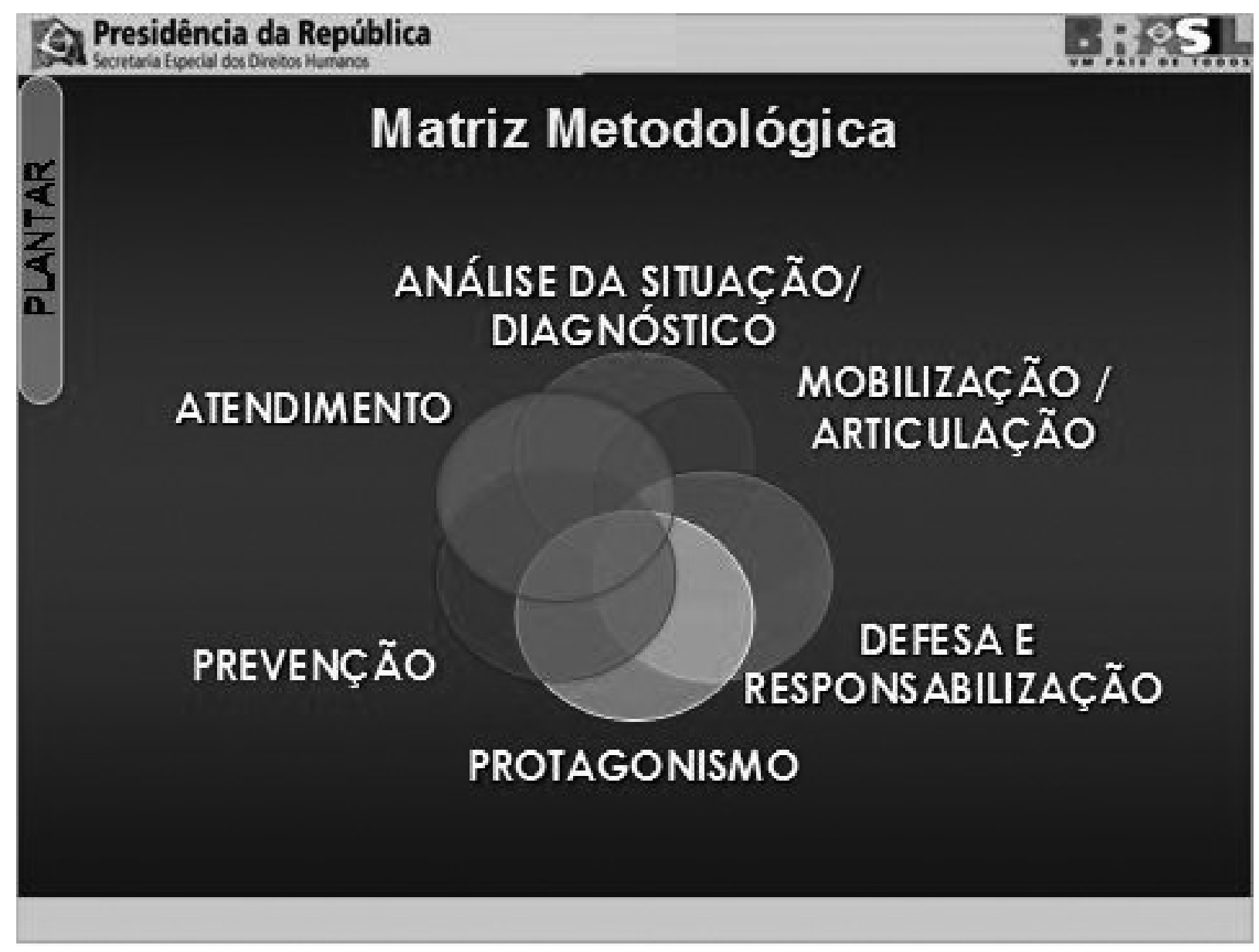

Fonte: ANVISA - Agência Nacional de Vigilância Sanitária.

Disponível em: http://www.anvisa.gov.br/hotsite/enaviss/300909/Idoso_MariaTabosa_3009.ppt\#520,25,Matriz Metodológica

A Universidade do Estado do Rio de Janeiro - UERJ, por intermédio da Sub-Reitoria de Extensão e Cultura, foi convocada pela coordenação executiva do Projeto PLANTAR a desenvolver o Diagnóstico Rápido Participativo (DRP), uma das ações estratégicas do projeto. Esta ação se desenvolveu pela aplica- ção de seis questionários, visando coletar dados para subsidiar a elaboração do DRP. Foram levantados dados sobre a população idosa e as condições das políticas públicas voltadas para pessoas idosas que residem na cidade do Rio de Janeiro. Os dados foram coletados por meio de entrevistas com instituições públicas, 
instituições não governamentais, movimentos sociais, lideranças comunitárias, ILPIs, fóruns e conselhos de direitos.

\section{Metodologia utilizada na aplicação dos questionários}

Os questionários foram desenvolvidos pela Secretaria Especial dos Direitos Humanos da Pre- sidência da República e são disponibilizados prontos para serem utilizados no formato estabelecido pela secretaria.

A cidade do Rio de Janeiro foi mapeada por regiões administrativas para identificação dos serviços e programas existentes no município e aplicação dos questionários, específicos para cada área de atuação ${ }^{8}$.

Quadro 1 - Síntese dos questionários, para uma visão global dos serviços. Rio de Janeiro, RJ, 2009

\begin{tabular}{|c|c|c|}
\hline Questionários & Serviços - Áreas & Serviços - Instituições / Programas \\
\hline Formulário 1 & Direitos da pessoa idosa & $\begin{array}{l}\text { Aplicado a dois órgãos de instância legalmente responsável } \\
\text { pela definição e controle de políticas públicas que dizem } \\
\text { respeito aos direitos do idoso, em âmbito municipal e } \\
\text { estadual. }\end{array}$ \\
\hline Formulário 2 & $\begin{array}{l}\text { Defesa e responsabilização } \\
\text { do idoso }\end{array}$ & $\begin{array}{l}\text { Aplicado a seis órgãos públicos ligados à defesa, nas áreas } \\
\text { de ação da polícia militar e do poder judiciário. }\end{array}$ \\
\hline Formulário 3 & Atendimento e prevenção & $\begin{array}{l}\text { Programas governamentais e não governamentais com } \\
\text { representação nas áreas de atenção à pessoa idosa, no } \\
\text { total de 13. Os critérios de participação foram: sorteio entre } \\
\text { os identificados na rede hospitalar, para escolha de um } \\
\text { hospital; o mesmo para escolha de uma Unidade de Pronto } \\
\text { Atendimento; para a indicação de dois projetos públicos e } \\
\text { dois privados; inclusão de três secretarias estaduais e uma } \\
\text { municipal, e de organismos públicos. }\end{array}$ \\
\hline Formulário 4 & Comunidade & $\begin{array}{l}\text { O objetivo desta entrevista foi levantar junto às lideranças } \\
\text { comunitárias e agentes de saúde informações sobre o } \\
\text { acesso dos idosos, que pertencem àquelas comunidades, } \\
\text { aos direitos e serviços voltados a este segmento no } \\
\text { município do Rio de Janeiro. } \\
\text { A escolha dos participantes foi por sorteio de quatro } \\
\text { representantes, entre os identificados no mapeamento. }\end{array}$ \\
\hline Formulário 5 & Movimentos sociais & $\begin{array}{l}\text { A cidade do Rio de Janeiro, pela sua diversidade cultural, } \\
\text { étnica e social, possui muitas organizações que emergem } \\
\text { de conflitos de violência urbana, projetos educacionais de } \\
\text { cunho nacional e internacional, e do exercício político pela } \\
\text { busca da efetivação dos direitos sociais. Este questionário } \\
\text { foi aplicado a oito organizações sorteadas entre as } \\
\text { mapeadas. }\end{array}$ \\
\hline Formulário 6 & $\begin{array}{l}\text { Instituições de Longa } \\
\text { Permanência Para Idosos } \\
\text { (ILPIs) }\end{array}$ & $\begin{array}{l}\text { As ILPIs são estabelecimentos para atendimento integral, } \\
\text { institucional, cujo público alvo são pessoas de sessenta (60) } \\
\text { anos ou mais, dependentes ou independentes, que não } \\
\text { dispõem de condições para permanecer com as famílias ou } \\
\text { em seu domicílio. } \\
\text { Foram sorteadas quatro instituições para aplicação do } \\
\text { questionário, sendo uma pública e três filantrópicas. }\end{array}$ \\
\hline
\end{tabular}

Os questionários foram aplicados no período de 05/11/2009 a 30/11/2009, por quinze alunos participantes do projeto, oriundos de cursos de graduação da UERJ. Os alunos faziam contato com os responsáveis pelos serviços e agendavam a visita. Antes da entrevista apresentavam uma carta da Sub-Reitoria de Extensão e Cultura da Universidade do Estado do Rio de Janeiro, na qual era solicitada autorização para aplicação do questionário e informados os objetivos. (Quadro 1)

As entrevistas foram analisadas pela metodologia do discurso do sujeito coletivo e pleno na garantia de seus direitos, sendo contextualizadas pelos demais dados, teorias e conceitos inerentes ao envelhecimento humano. 


\section{Diagnóstico da aplicação dos questionários - dificuldades e facilidades encontradas}

Em 16 de outubro de 2009, realizou-se uma reunião nas dependências da UERJ, com o objetivo de promover o treinamento sobre o Projeto PLANTAR e sua operacionalidade pela execução do DRP.

Dessa reunião de integração das instâncias que fazem parte do Sistema de Garantia de Direitos participaram doze autoridades representantes dos órgãos governamentais envolvidos e os quinze alunos da UERJ que atuaram na aplicação dos questionários:

- Sub-Reitoria de Extensão e Cultura da UERJ, três representantes;

- Secretaria de Ação Social e Direitos Humanos, um representante;

- Secretaria do Envelhecimento Saudável e da Qualidade de Vida-Município do Rio de Janeiro, quatro representantes;

- Secretaria Especial de Direitos Humanos, um representante;

- Fórum Nacional de Educação e Direitos Humanos, dois representantes;

- UERJ/UNATI - Universidade Aberta da Terceira Idade, um representante;

- $\quad$ Alunos do curso de graduação da UERJ, das áreas de Serviço Social, Nutrição, Pedagogia, Letras e Comunicação Social.

A equipe da UERJ/UnATI reuniu-se o dia 17 de outubro de 2009 para mapear os serviços existentes no município do Rio de Janeiro que estivessem integrados numa rede de atendimento ao idoso. Frente ao número elevado de instituições e ao pouco tempo estimado para realização da pesquisa, optou-se por selecionar as de expressivo trabalho na área do envelhecimento humano e pela escolha por sorteio, no caso de um grande número de instituições com o mesmo perfil de serviços. Algumas instituições foram bastante colaborativas com a pesquisa, facilitando a transmissão das informações dos dados e abreviando o tempo de espera dos alunos. Outras instituições burocratizaram o atendimento, dificultando o roteiro planejado. Alguns gestores não entenderam o teor do projeto, chegando mesmo a desconhecer sua participação na rede de atenção ao idoso.

\section{Sistematização, análise e compilação das informações coletadas}

Os questionários aplicados foram compilados em pastas, por especificidade de serviços e semelhança na característica ao atendimento, conforme demonstrativo abaixo.

\section{Formulário 1}

A equipe de pesquisadores iniciou a análise dos dados pelo formulário que trata dos conselhos de direitos. Os dois conselhos entrevistados ocupam espaços públicos e têm caráter deliberativo; sentem muita dificuldade na obtenção de material de consumo para dar andamento à rotina dos conselhos e implementar ações e campanhas. Esses conselhos revelaram conhecer o plano de enfrentamento a favor dos direitos da pessoa idosa. Com relação às ações em parceria na fiscalização do exercício desses direitos contam com o Ministério Público e Defensoria Pública.

\section{Formulário 2}

Trata das instituições voltadas à defesa e implementação das leis de direitos sociais da pessoa idosa. As instituições de defesa também ocupam espaço público, à exceção de uma delas. Foi identificada boa articulação entre as instituições atuantes nas áreas de ação do corpo de bombeiros, das polícias militar e rodoviária e do poder judiciário. A Promotoria de Justiça de Proteção ao Idoso espera uma boa articulação na efetivação da rede para que venha cumprir o Art. 74 do Estatuto do Idoso. O Núcleo de Atendimento à Pessoa Idosa citou a articulação com o Governo Federal, através do PRONASCI (Programa Nacional de Segurança Pública com Cidadania), que atende mulheres vítimas de violência. A Delegacia Especial de Atendimento à Pessoa Idosa demonstrou que vem se articulando com os órgãos como Ministério Público, Defensoria Pública, áreas da saúde e de orientação.

\section{Formulário 3}

O formulário 3, que trata do atendimento e prevenção, reuniu grande número de dados para análise do diagnóstico. Os programas governamentais já estão incluindo em seus planejamentos ações efetivas no trato com a pessoa idosa, como 
campanhas, projetos e orientações acerca dos direitos sociais desse segmento populacional. Os programas de governo demonstram bastante preocupação com os indicadores que apontam para o crescimento da expectativa de vida do brasileiro. Esses programas articulam-se visando um empenho comum no fortalecimento da rede de atenção ao idoso. Os programas de cunho não governamental trabalham na perspectiva do fortalecimento de centros de convivência e sociabilidade dos idosos. Estes programas declararam ter conhecimento de ações governamentais de combate à violência, mas informaram não terem participado ativamente de sua construção. Eles desenvolvem suas ações em parceria com outras instituições ou com a colaboração de pessoas ligadas às instituições. Quando perguntados sobre a articulação com a rede, informaram que estão articulados com a rede informal.

\section{Formulário 4}

Trata do levantamento de dados oriundos das lideranças comunitárias. Estas lideranças demonstraram bastante preocupação em efetivarem ações e políticas para o atendimento do idoso de suas comunidades. Algumas informaram que, nos últimos anos, o Poder Público esteve mais próximo dos seus anseios. $\mathrm{Na}$ análise, percebe-se que as comunidades estão muito participativas e organizadas politicamente na busca pela execução do compromisso do Poder Público na implementação de programas, ações e projetos de efetiva consistência técnica em seus espaços.

\section{Formulário 5}

$\mathrm{Na}$ análise ao formulário 5, é necessário refletir sobre os movimentos sociais e a importância dessas organizações no contexto social. Segundo Frei Betto", "movimentos sociais são organizações da sociedade civil que pressionam a sociedade política (Estado e instituições afins) visando à defesa e/ou conquista de direitos (humanos, civis, políticos, econômicos, ecológicos etc).” Por serem muito organizados, os movimentos sociais entrevistados no DRP apresentaram informações bem consistentes sobre a missão de suas lutas e plena consciência de seus direitos. Esses movimentos possuem larga experiência nas lutas sociais e efetiva participação nos movimentos políticos, participam ativamente de fóruns de discussão de Políticas Públicas para área do envelhecimento humano e também executam algumas ações voltadas aos idosos vinculados às suas categorias. Eles procuram estar lado a lado com o Poder Público na construção da articulação da Rede de Promoção dos Direitos da Pessoa Idosa.

\section{Formulário 6}

Os dados do formulário 6 tratam de um dos setores mais complexos da Rede de Promoção dos Direitos da Pessoa Idosa, as Instituições de Longa Permanência para Idosos. Historicamente, essas instituições sempre existiram à margem da sociedade. Hoje, porém, frente ao aumento da expectativa de vida pelo qual passa o país, deve-se refletir sobre um novo paradigma para estas instituições. Elas devem caminhar junto às políticas de envelhecimento, capacitar seus recursos humanos e criar formas de articulação com outras instituições de atendimento à pessoa idosa. As ILPIs de caráter filantrópico entrevistadas apresentam alguma fragilidade no aspecto econômico e também na execução das Políticas Públicas. Estas instituições encontram muita dificuldade para se manter e, ao mesmo tempo, atender aos padrões exigidos pela Vigilância Sanitária, bem como de se adequarem à Resolução RDC 283/2005 ${ }^{10}$ que trata das normas de funcionamento das ILPIs. A única ILPI de caráter público, por ter passado recentemente pela troca de gestão governamental, implementa ações governamentais em consonância com as políticas de envelhecimento no país e implementa as diretrizes de governo, às quais se subordina. Foi sugerido pelas ILPIs, melhorias nos serviços de atendimento à pessoa idosa, melhorias no transporte público, urbanismo e lazer.

\section{Conclusão}

Acreditava-se que não haveria muita dificuldade no contato com as instituições participantes do diagnóstico, por se tratar de missão governamental e de um projeto inovador na área do envelhecimento humano e das Políticas Públicas, e por essa proposta ser considerada como marco valioso no âmbito das políticas públicas em defesa da pessoa idosa. No entanto, algumas instituições não compreenderam a proposta, demonstrando desconfiança junto às ações descritas no diagnóstico 
e também nas parcerias que foram pactuadas no projeto PLANTAR.

Superados os desafios, ficou claro que o município do Rio de Janeiro possui uma rede de serviços - programas, projetos e ações bastante comprometidas com as diretrizes traçadas em conferências nacionais, estaduais e municipais, fóruns, conselhos e programas de governo mas não está articulada. A rede que está posta existe constitucionalmente, mas seus agentes só interagem informalmente. Quando o usuário necessita de um atendimento especializado, o profissional que está à frente do programa estabelece contato com um colega da área desejada a fim de garantir o atendimento especializado, sem envolver a instituição. Alguns programas interagem entre si, mas a grande maioria não se articula às ações para que se criem maiores facilidades no atendimento ao idoso e poder fornecer esclarecimentos adequados sobre as funções de cada instituição. Assim, poderiam contribuir para minimizar a duplicidade de informações e de registro de ocorrências, de modo a não realizar vários atendimentos ao mesmo indivíduo, podendo atender a um número bem maior de idosos sem assistência e carentes de orientações, atuando de modo eficaz.

O Diagnóstico Rápido Participativo, como uma das ferramentas de articulação do PLAN. TAR, constitui-se num amplo projeto de pesquisa extensionista na produção de conhecimentos, possibilitando, de forma participativa, a troca de experiências e a identificação de obstáculos e de oportunidades.

\section{Contribuições dos autores}

Sandra Rabello trabalhou na concepção, na pesquisa, na metodologia e na redação final.

Conceição Ramos de Abreu trabalhou na pesquisa, na metodologia e na redação final.

\section{Referências}

1. BRASIL. Presidência da República. Secretaria Especial dos Direitos Humanos. Conselho Nacional dos Direitos do Idoso. $1^{\text {a }}$ Conferência Nacional dos Direitos da Pessoa idosa. Regimento - Construindo a Rede Nacional de Proteção e Defesa da Pessoa Idosa-RENADI. 23 a 26 de maio de 2006. Disponível em: <http://www.mj.gov.br/sedh/ct/cndi/i_ conferencia_idoso.htm.> Acesso em : 15 mar. 2010.
2. BRASIL. Presidência da República. Secretaria Especial dos Direitos Humanos. Conselho Nacional dos Direitos do Idoso. $2^{\mathrm{a}}$ Conferência Nacional dos Direitos da Pessoa Idosa. Avaliação da Rede Nacional de Proteção e Defesa da Pessoa Idosa: avanços e desafios. 18 a 20 de março de 2009. Disponível em: <http://www.mds.gov.br/noticias/conferencia-em-brasilia-df-avalia-rede-de-protecao-e-defesa-dos-direitos-dos-idosos> Acesso em: 17 mar. 2010.

3. BRASIL. Constituição (1988). Constituição da República Federativa do Brasil: promulgada em 5 de outubro de 1988. Organização do texto: Juarez de Oliveira. 4. ed. São Paulo: Saraiva, 1990. 168 p. (Série Legislação Brasileira).

4. BRASIL. Lei 8.842, de 4 de janeiro de 1994. Dispõe sobre a Política Nacional do Idoso, cria o Conselho Nacional do Idoso e dá outras providências. Diário Oficial [da] República Federativa do Brasil, Poder Executivo, Brasília, DF, 5 jan.1994.

5. BRASIL. Lei $\mathrm{n}^{\circ} 10.741$, de 1 de outubro de 2003, "dispõe sobre o Estatuto do Idoso e dá outras providências”. Diário Oficial [da] República Federativa do Brasil, Poder Executivo, Brasília, DF, 3 out. 2003.

6. BRASIL. Presidência da República. Secretaria Especial dos Direitos Humanos. Fórum Nacional de Educação em Direitos Humanos - FNEDH. Convênio 704572/2009-SPDDH/ SEDH/PR - Plano Técnico de Articulação de Rede de Promoção dos Direitos da Pessoa Idosa - PLANTAR. Brasília, 2009. Disponível em: <http://www.forumedh.org.br/> Acesso em : 15 jan. 2010

7. BRASIL. Presidência da República. Secretaria de Direitos Humanos. Secretaria Especial dos Direitos Humanos. Coordenação Geral dos Direitos do Idoso. Plano Operativo Local para a Promoção e Defesa dos Direitos da Pessoa Idosa é tema de seminário no RJ. Disponível em: http://www. direitoshumanos.gov.br/noticias/ultimas_noticias/2010/03/ MySQLNoticia.2010-03-01.2132/?searchterm=projeto plantar. Acesso em : 17 jan. 2010.

8. RIO DE JANEIRO. Prefeitura da Cidade do Rio de Janeiro. Idosos: um perfil estatístico da Terceira Idade na cidade do Rio de Janeiro. Rio de Janeiro. Instituto Pereira Passos, fev. 2005. Coleção Estudos da Cidade (Publicado em Rio Estudos $\mathrm{n}^{\circ}$ 146. Disponível em: http://www.armazemdedados.rio.rj.gov.br/ Acesso em: 15 mar. 2010.

9. BETTO, Frei; VERÍSSIMO; Luís Fernando. Os movimentos sociais na luta contra a pobreza. O desafio ético. In: Leituras cotidianas, $\mathrm{n}^{\circ} 294,3$ de janeiro de 2007. Disponível em: http://www.pfilosofia.xpg.com.br. Acesso em: 13 nov. 2009.

10. BRASIL. Ministério da Saúde. Agência Nacional de Vigilância Sanitária-ANVISA. Resolução RDC n 283, de 26 de setembro de 2005. Aprova o Regulamento Técnico que define normas de funcionamento para as Instituições de Longa Permanência para Idosos. Diário Oficial [da] República Federativa do Brasil. Poder Executivo, Brasília, DF, 2005. 


\begin{abstract}
Objectives: This aim of this report is to describe the participation of the State University of Rio de Janeiro (UERJ) in applying the questionnaire of the pilot project PLANTAR, through the participatory RAPID diagnosis. Methods: The methodology of the PLANTAR project - Plan for Technical Coordination Network for Protecting and Defending the Rights of the Elderly integrates policies for building a common agenda of work among governments, civil society and international governments, through the application of six questionnaires that allow collecting data on the local elderly population and raise the conditions of public policies aimed at older people. Results: We identified the need to invest in the project in the areas of staff training, learning resources, information to the population through the media, and greater participation of non-governmental organizations. Conclusions: the city of Rio de Janeiro has a network of services, but they are not integrated, which stops effective performance.

Keywords: Social Service Network; Research; Participatory Appraisal; Public Social Policies
\end{abstract}

